$\left.\begin{array}{l}\text { Sournals } \\ \text { INTERNATIONAL JOURNAL OF } \\ \text { ORGANIZATIONAL LEADERSHIP }\end{array}\right) \begin{gathered}\text { INDUSTRIAL } \\ \text { MANAGEMENT } \\ \text { INSTITUTE }\end{gathered}$

\title{
Investigating the impact of competitive strategy, knowledge management and the acceptance of electronic commerce on financial performance (Case Study: Bank Shahr in East Azerbaijan Province)
}

\author{
Seyed Reza Jafarian ${ }^{1 *}$, Mehdi Zeynali ${ }^{2}$ \\ ${ }^{1}$ Department of Accounting, Science and Research Branch, Islamic Azad University, Ardabil, Iran \\ ${ }^{1}$ Department of Accounting, Ardabil Branch, Islamic Azad University, Ardabil, Iran. \\ ${ }^{2}$ Department of Economy and Accounting, Tabriz Branch, Islamic Azad University, Tabriz, Iran.
}

\section{Keywords:}

Competitive Strategy, Knowledge Management, Acceptance of Electronic Commerce, Financial

Performance of Shahr Bank

\section{Received}

05 September 2015

Received in revised form 27 July 2016

Accepted

01 August 2016

Correspondence:

Citybank_7@yahoo.com

\section{Abstract}

\begin{abstract}
The aim of this study was to investigate the impact of competitive strategy, knowledge management, and the acceptance of electronic commerce on financial performance in Shahr Bank in East Azerbaijan. The statistical population of this research included all the employees $(\mathrm{N}=85)$ of Shahr Bank in East Azerbaijan. Data gathering was accomplished through using a questionnaire which its validity and reliability were measured and confirmed. In order to analyze the data, the inferential statistics, regression, and correlation analysis were conducted. The results indicated that competitive strategy, knowledge management, and the acceptance of electronic commerce have a positive impact on the financial performance of Shahr Bank.
\end{abstract}

Increasing development of information and communication technology has had profound impacts on business processes and Internet as the most effective base for electronic marketing. It has paved the way for companies to enter the international markets and customer service 
with its global coverage. In addition, knowledge and management are of interest in all organizations (Bengtsson, Boter, \& Vanyushyn, 2007). The results of various research studies and statistics indicate that those countries, which have overtaken the other countries in knowledge and competitive strategies, are in higher rank in terms of competitive growth and economic power. On the other hand, companies with poor economic climate suffer from poor foundation, knowledge infrastructure, and the applied strategies (Moradi, \& Shafahi, 2005). In the era of information and communication technology, knowledge is considered as the critical factor for organizations in achieving stable competitive advantage. In the process of shifting from the industry-based economy to the knowledge-based economy, organizations have attempted to promote their competitive power through relying on the knowledge and information and using it in the process of business. In order to answer why some organizations are successful in the competition, we need to understand the leading role of knowledge and strategies in these organizations (Abtahi \& Salavati, 2006).

Generally, organizations rely on two major categories of assets including tangible and intangible assets. So far, obtaining and optimizing tangible assets such as machinery and equipment had attracted the attention of many organizations. Today, organizations have realized that intangible assets such as intellectual capital, experience, organizational knowledge, and information will contribute to their success and survival (Shipside, 2002). Today, companies have concluded that they must pay more attention to what they know or intellectual capital than what they have or physical capital (Hosseini, Ghazizadeh, \& Abbasi Esfangani, 2009).

Realizing the importance and the critical role of knowledge management, organizations are encouraged to apply these systems. However, in reality, due to lack of a clear understanding about what organizations want to achieve, they cannot ideally and optimally design and implement these systems (Hsu, 2012). If the processes of knowledge management such as creating knowledge, obtaining knowledge, sharing knowledge, applying knowledge and maintaining knowledge are applied in the organizations in a systematic and organized way, their profound impacts on creating competitive advantage in different units of organization can be observed (Slater \& Olson, 2001).

\section{The Literature Review}

Capital market is of great importance, because it provides a common foundation for evaluating companies' performance. Capital market plays a critical role in economic development of countries. This market not only activates stagnant capital and money through the companies, but also acts as an index of economic prosperity in countries. Therefore, it is necessary to pay attention to this market and its primary foundations of decision-making. Obviously, the investing goal of investors in a company is to earn returns proportional to their investments. If a company is successful in adding value, not only investors and company insiders will benefit this added value, but the society will also benefit at an extended level. Measuring the performance in the process of decision-making with regard to the importance of capital market is one of the most important subjects in the field of financial economy (Del Aguila-Obra \& Padilla-Melendez, 2006). 
Today, there are various models for companies to develop and enter the market. Therefore, one approach or combined approaches must be applied according to the environmental requirements and market conditions, so that companies can stabilize their presence and increase their market share (Moradi \& Shafahi, 2005).

On the other hand, companies with poor economic conditions suffer from poor foundation, knowledge infrastructure, and the applied strategies (Moradi \& Shafahi, 2005).

Knowledge, electronic commerce, and strategy have become three powerful tools for the companies in order to improve their organizational performance in the market. It is very important for companies to identify a strategy with high knowledge management ability and high level of electronic commerce acceptance in the knowledge-based economy, so that they can show the highest level of performance (Rust \& Espinoza, 2006). In order to raise the necessity of implementing the plans of knowledge management system as well as using information technology and competitive strategies to promote financial and non-financial performance in the organizations, it is essential to accurately identify the consequences of using these plans in different units of an organization (Bock et al., 2005; Pennington, 2003). Until now, several studies have been conducted on the knowledge management concepts, processes, strategies, and performances; however, due to the difficult competitive conditions, organizations seek to find that whether implementing the knowledge management plans, electronic commerce, and competitive strategies can create competitive advantage and competitive differentiation and also improve the financial performance or not.

In the era of information and communication technology, knowledge is considered as the critical factor for organizations in order to achieve sustainable competitive advantage. We need to understand the leading role of knowledge and strategies in these organizations for answering the question that why some organizations are successful in competition (Abtahi \& Salavati, 2006). Organizations are encouraged to apply these systems in order to realize the importance and critical role of knowledge management. In reality; however, they cannot optimally design and implement these systems due to the lack of a clear understanding about what organizations really want (Hsu, 2012). It is necessary to accurately recognize the direct consequences of using these plans in different organizational unites. The extended study on concepts such as implementing knowledge management plans and using information technology and competitive strategies to promote financial and non-financial performance in the organizations have done (Bock et al., 2005; Pennington, 2003).

In recent years, knowledge management has become an important and critical subject. Commercial banks can sustain their long-term advantages through the strength of their knowledge and scholars have found that knowledge management contrary to other managements has long-lasting consequences and is not transient. The competitive banking environments have become more complicated and are evolving more rapidly. In fact, the pace of change in most banks is more than its accountability and adaptation pace. Continuous changes of knowledge have created new imbalance in banks. Therefore, just those banks which adopt and apply the best competitive strategies can survive. Researchers believe that resultoriented competitive strategies and organizational survival are possible through knowledge management, so that new knowledge can be created in the organization continuously (Kiang, \& Chi, 2001; Bengtsson, Boter, \& Vanyushyn, 2007). Shahr Bank is not an exception and 
establishing knowledge management in there can contribute significantly to the improvement of managers and employees' performance. Moreover, it facilitates the competitive strategies implementation and consequently the improvement of financial and non-financial performance of the organization.

Shahr Bank, as one of the largest private banks, has realized the importance of Internet banking, thus it has gathered an appropriate collection of information and services. Although, the development of infrastructures and the initial stage of developing electronic commerce in this bank have not been completed, it seems that the technological activities are more limited than the real capacities and demands of customers. According to experts, this indicates that the existing infrastructures are not applied sufficiently; therefore, this issue must be considered in goal-setting and policy-making of electronic banking. Therefore, this research can investigate the applied strategies, knowledge management establishment, and the usage of electronic banking services in Shahr Bank and measure the relationship between these factors and financial performance.

Therefore, in this study, the impacts of competitive strategy, knowledge management, and the acceptance of electronic commerce on financial performance of Shahr Bank will be investigated.

\section{Competitive Advantage}

Competitive advantage is a collection of unique abilities of an economic unit which allows it to penetrate into desired markets and provide the unit to dominate over the competitors. In order to define competitive advantage of an economic unit, management must carry out thorough evaluation of external and internal environment of the unit. When a manager finds strength in the enterprise which meets the need of the market and creates relative dominance in the market, he can achieve a competitive advantage. Companies can have competitive advantages in proportion to their competitors in terms of technology, management, and marketing.

Philip Selznick was the first one who used the term of competitive advantage in 1957. Besides strengths and weaknesses, business managers must also consider the impacts of the environment on the performance of their business and predict the probable changes. In this case, they must whether change the market in favor of their business or change the business in accordance with the market. In evaluating the market, the manager must consider both the current and future requirements of the market. Competitive advantage of business is the result of strategic planning. In this planning, the trajectory of an economic unit is mapped from the potential abilities toward the opportunities. The managers must adopt the best strengths of the business; however, their planning must not be based on vulnerable domains of business. Having competitive advantage is not necessary for an enterprise. However, this characteristic allows the business to take its own economic course and limit competitors' limitations to achieve better status in the market. If other competitors do not have any special competitive advantage, their survival in the competition field will be ambiguous.

The concept of competitive advantage is directly related to the customers' intended values, so that in a comparative spectrum, if the values offered by an organization are more consistent with customers' intended values, it will be concluded that the organization has an advantage in one or more competitive criteria over its competitors (Mehri \& Khodadad Hosseini, 2005). 
In a knowledge-based economy, products and organizations live and die based on the knowledge and the most successful organizations are those which use this intangible asset in a better way. Researches indicate that despite the decrease in the efficiency of traditional resources such as money, land, and machinery, knowledge is the source of promoting business performance. From strategic viewpoint, knowledge and intellectual capital are used to create and improve organizational value and the success of an organization depends on its ability to manage this rare source.

The revolution of information technology, the formation of information and network community as well as the rapid development of high technologies, especially in communication, computer, and engineering have transformed the development pattern of global economy since 1990. As a result of these developments, knowledge as the most important capital has been substituted for financial and physical capitals in the world economy.

Significantly, the market has realized the value of knowledge and other invisible factors in the process of value creation. Recently, the extent of this hidden value has been changed.

The dimensions of knowledge management are divided into three groups of organizational culture, organizational structure, and information technology. Implementation of knowledge management in the organization requires simultaneous activities in three domains of organizational culture, organizational structure, and information technology (software system of knowledge management).

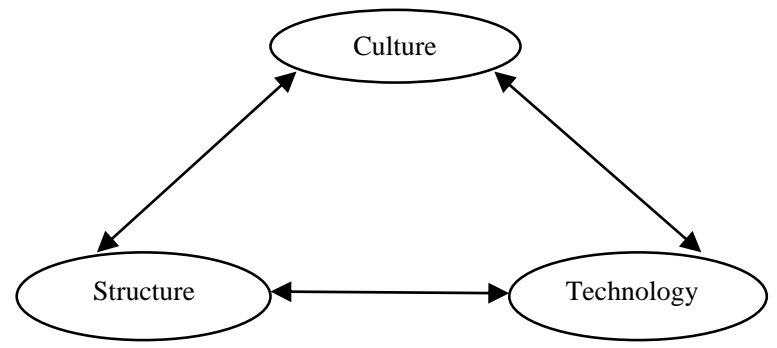

Figure 1. The dimensions of knowledge management

In the first half of the 1990s, the Internet highly developed and began to go beyond the academic and military domains and involved more users in society. On the one hand, developing global website, related standards, and protocols attracted attention of more users to the Internet and employed the information technology tools in public, and on the other hand, provided these facilities for companies and institutions in a way that they could inform in an easier and less expensive way. In the second half of the 1990s, the users and companies were increasingly faced with the innovations and information technology improvements as a foundation for electronic business models. In this era, one of the most important developments of the Internet occurred as the foundation for electronic commerce. These developments were related to ability of adding information processing. The ability to process the information provided many facilities for electronic commerce and developed electronic commerce models as well as increasing the efficiency of these models. In this period, electronic commerce models and the volume of transactions conducted by these models grew exponentially. In addition, most of electronic commerce models were based on final users and were classified as business to customer. Electronic commerce systems play an important role in adopting new 
strategies of customer management including direct communication between buyers and sellers, removing the limitations and saving time, and supporting interactional activities.

Electronic commerce can contribute to the improvement of services through direct communication. The first benefit of electronic commerce is to offer information about the product to the customers through internet electronic booklets or buying guides. Table 1 presents the components of electronic commerce which are used in information technology.

Table 1

The Components of Electronic Commerce

\begin{tabular}{lc}
\hline Components & Items \\
\hline Improvement of Product & Improvement; Market Regulation; After Sales Services; Wide Reflection \\
A New Sales Channel & Transformation; Training Technology Organization; Communication with Customers \\
Direct Savings & Redefining; The Ability of New Product; New Commercial Models \\
\hline
\end{tabular}

In a world where product differentiation is becoming more and more difficult, life cycle becomes more finite. Since customers have a limited time, electronic commerce provides an opportunity for offering potential new strategies and promoting trademarks. In this regard, the quality of advertisements is the most important factor for improving the products. Safarzadeh et al. (2013) studied the impact of knowledge management strategies on innovation and organizational performance. This study was applicable in terms of aim and descriptive in terms of data collection. In their study, the relationship between variables was studied directly to investigate the impact of knowledge coding and knowledge personalization on innovation and performance. The findings of their study indicated that with 99 per cent confidence level, the variables of innovation and organizational performance have a direct relationship with coding. In addition, innovation and organizational performance are directly related to knowledge personalization with 99 per cent confidence level. The results of their study also revealed that innovation has a direct impact on the organizational performance. According to the results, knowledge personalization and knowledge coding have positive effects on innovation and organizational performance and there is a positive and significant relationship between innovation and organizational performance.

Hsu (2012) in his study investigated the impact of competitive strategies, knowledge management, and the acceptance of electronic commerce on the performance of the organization. The results of his study indicated that competitive strategies, knowledge management, and the acceptance of electronic commerce had significant positive impact on the performance of the organization.

Lee and Chou (2012) investigated the effects of knowledge management strategy on the knowledge creation ability of individuals and the organizations' performance. The results of their study indicated that knowledge management strategy in an organization significantly affects on the knowledge creation ability of that organization. Moreover, knowledge creation ability positively affects the individual performance.

Kasten (2011) studied knowledge management and its impact on organizational performance. In this study, different organizations from different fields such as health centers, 
financial services, and insurance were investigated. The results indicated that knowledge strategies which are adopted by the organization can be categorized based on some dimensions such as organization's tendency for accumulating knowledge by the members of the organization or technology, organization's tendency to be active or passive, collecting and developing knowledge, and finally the depth and domain in which the organization looks for knowledge and develops it. In addition, findings suggested that there is a significant relationship between the strategy type of an organization's business and the features of knowledge strategy.

Chang Lee, Lee, and Kang (2005) investigated 101 Korean companies and introduced an index which was named KMPI to measure knowledge management performance. They suggested that through increasing this index which includes the main components of knowledge process cycle including creation, accumulation, sharing, and using and internalizing knowledge as well as the indices of organizational performance such as stock price, the rate of obtained price, and research and development prices.

\section{Method}

This study had an ex post facto or casual design in terms of work nature. In this research, in order to develop the theoretical framework of study library studies have been conducted. Moreover, data was collected through using field method. The present study is a crosssectional one in terms of time and is applicable in terms of results and descriptive in terms of aim. Figure 2 presents the general framework of study.

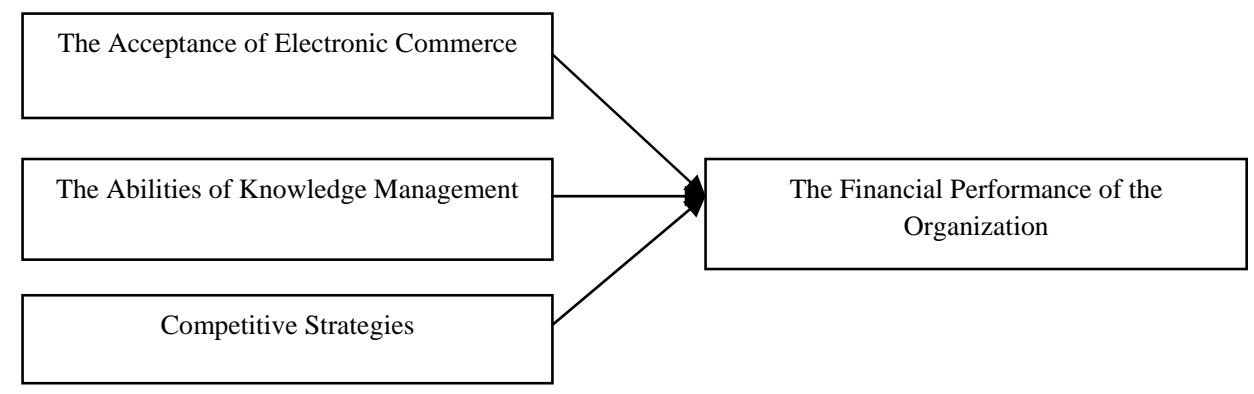

Figure 2. The model of research (Hsu, 2012)

Dependent variable of this study was the financial performance of the organization and independent variables include the consumer acceptance of electronic commerce, the abilities of knowledge management, and competitive strategies. The statistical population of this study includes all executive employees of Shahr Bank in East Azerbaijan Province. In this study, data was collected through questionnaire and interview. Questionnaires are popular tools for conducting researches and are considered as direct method of collecting data.

The reliability of the questionnaire was verified through applying Cronbach's alpha coefficient. The questionnaires were distributed among 30 members of statistical sample. After collecting the questionnaires, the value of Cronbach's alpha coefficient was calculated separately for different domains. The results are demonstrated in Table 2. 
Table 2

The Reliability of Questionnaire to the Separation of Various Domains

\begin{tabular}{ccc}
\hline Variable & Number of Questions & Cronbach's Alpha Coefficient \\
\hline Competitive Strategy & 9 & 0.84 \\
Knowledge Management & 10 & 0.73 \\
The Acceptance of Electronic Commerce & 9 & 0.86 \\
\hline
\end{tabular}

The results in Table 2 indicate that since the value of Cronbach's alpha coefficient for the variables are more than 0.6 , it is concluded that this questionnaire shows acceptable reliability.

\section{Results}

Regression analysis was used to test the normality of data. Table 3 summarizes the results of regression analysis. In order to investigate the impacts of variables, simple regression analysis has been used to test the first hypothesis. Table 4 shows the results of one-way analysis of variance (ANOVA).

Table 3

The Results of Regression Regarding the Impact of Competitive Strategy on Financial Performance

\begin{tabular}{ccccc}
\hline Model & Correlation Coefficient & $\begin{array}{c}\text { Coefficient of } \\
\text { Determination }\end{array}$ & $\begin{array}{c}\text { Adjusted Coefficient of } \\
\text { Determination }\end{array}$ & Standard Error \\
\hline 1 & 0.57 & 0.33 & 0.32 & 0.54 \\
\hline
\end{tabular}

Table 4

The Results of one-way analysis of variance (ANOVA)

\begin{tabular}{cccccc}
\hline Model & Chi-Square & Degree of Freedom & Mean Square & $f$ & Sig. \\
\hline Regression Impact & 34.61 & 1 & 34.61 & 112.74 & 0.00 \\
Remainder & 68.77 & 84 & 0.30 & & \\
Total & 103.38 & 85 & - & & \\
\hline
\end{tabular}

*Regression parameter: Competitive strategies

*Dependent variable: Financial performance

The coefficient of determination in Table 3 indicates that the competitive strategies had a significant impact on the financial performance determines 33.5 per cent of the dependent variable. In addition, $f$ in Table 4 indicates that regression was significant with 99 per cent confidence level. To answer the second hypothesis which stated that the abilities of knowledge management had a significant impact on the financial performance of Shahr Bank, simple regression was used. The results of regression are summarized in Tables 5 and 6.

Table 5

The Results of Regression Regarding the Impact of Knowledge Management Abilities on Financial Performance (Model Summery)

\begin{tabular}{cccc}
\hline Model & Correlation Coefficient & $\begin{array}{c}\text { Coefficient of } \\
\text { Determination }\end{array}$ & $\begin{array}{c}\text { Adjusted Coefficient of } \\
\text { Determination }\end{array}$ \\
\hline 1 & 0.45 & 0.20 & 0.20 \\
\hline
\end{tabular}

Table 6

The Results of Variance Analysis (ANOVA)

\begin{tabular}{cccccc}
\hline Model & Chi-Square & Degree of & Mean Square & $f$ & Significance Level \\
\hline
\end{tabular}




\begin{tabular}{cccccc}
\hline \multicolumn{5}{c}{ Freedom } & \\
\hline Regression Impact & 21.19 & 1 & 21.19 & 57.74 & 0.00 \\
Remainder & 82.19 & 84 & 0.36 & & \\
Total & 103.38 & 85 & - & & \\
\hline
\end{tabular}

* Regression parameter: The abilities of knowledge management

* Dependent variable: Financial performance

The coefficient of determination calculated through regression test in Table 5 indicates that the knowledge management had a significant impact on the financial. In addition, $f$ in Table 6 indicates that regression was significant. Simple regression was used to test the third hypothesis which stated that the acceptance of electronic commerce had a significant impact on the financial performance of Shahr Bank. The results of regression are summarized in Table 7 and 8.

Table 7

The Results of Regression Regarding the Impact of the Acceptance of Electronic Commerce on Financial Performance (Model Summery)

\begin{tabular}{ccccc}
\hline Model & $\begin{array}{c}\text { Correlation } \\
\text { Coefficient }\end{array}$ & $\begin{array}{c}\text { Coefficient of } \\
\text { Determination }\end{array}$ & $\begin{array}{c}\text { Adjusted Coefficient of } \\
\text { Determination }\end{array}$ \\
\hline 1 & 0.60 & 0.36 & 0.36 & 0.54 \\
\hline
\end{tabular}

Table 8

The Results of Variance Analysis (ANOVA)

\begin{tabular}{cccccc}
\hline Model & Chi-Square & $\begin{array}{c}\text { Degree of } \\
\text { Freedom }\end{array}$ & Mean Square & $f$ & Significance Level \\
\hline Regression Impact & 38.10 & 1 & 38.10 & 130.77 & 0.00 \\
Remainder & 65.27 & 84 & 0.29 & & \\
Total & 103.38 & 85 & - & & \\
\hline
\end{tabular}

* Regression parameter: The acceptance of electronic commerce

*Dependent variable: Financial performance

Table 7 indicates that the acceptance of electronic commerce had a significant impact on the financial performance.

According to the results, it can be concluded that knowledge, electronic commerce, and strategy are considered as three powerful tools for companies to expand their organizational performance in the market. It is of primary importance for companies to identify a strategy with high knowledge management ability and high level of electronic commerce acceptance in the knowledge-based economy so that they can show the high level of performance.

\section{Discussion and Conclusion}

According to the obtained data, it can be concluded that the components of competitive strategies had a great impact on the financial performance of the employees of Shahr Bank. The literature survey indicated that the subject and purpose of this study was in line with the previous studies in this field. Competitive strategies refer to a set of substantial abilities in an economic unit which allows it to penetrate into desired markets and provides a ground to dominant over the competitors. In order to define competitive advantage of an economic unit, the management section should initially carry out a thorough evaluation of external and internal environment of the unit. When the managers find strength in an enterprise which meets the 
needs of market and creates relative dominance in the market, it can be said that he has achieved a competitive advantage. Companies can enjoy competitive advantages in proportion to their competitors in terms of technology, management, and marketing.

Safarzadeh, Naderi, and Enayaty (2013) investigated the impact of knowledge management strategies on the innovation and organizational performance. In order to investigate the impact of knowledge coding and knowledge personalization on the innovation and performance, the relationship between variables was studied directly. The values of $t$ corresponding to the standardized values and path coefficients indicated that with 99 per cent confidence level, there was a direct relationship between the variables of innovation and organizational performance and coding. In addition, innovation and organizational performance are directly related to knowledge personalization with 99 per cent confidence level. The corresponding $t$ values also indicated that with 99 per cent confidence level, there was a direct relationship between innovation and organizational performance. According to the results, knowledge personalization and knowledge coding had positive impacts on innovation and organizational performance and furthermore there was a significant positive relationship between innovation and organizational performance. Seyed Danesh, Saremi Rad, Nejad Mobasher, and Seyed Danesh (2012) investigated the relationship between improved knowledge management and the organization's operating performance. They experimentally evaluated the importance of knowledge management in the performance of organization's operational processes. The results of a common interpretation of knowledge management among the executive employees indicated that how the improved knowledge can be used in designing and implementing an operational unit. The results of a logistic operation support the positive relationship between the knowledge management process and the performance of the organization.

Hsu (2012) investigated the effects of competitive strategies, knowledge management, and the acceptance of electronic commerce on the organization's performance. The results indicated that competitive strategies, knowledge management, and the acceptance of electronic commerce had significant positive impacts on the organization's performance.

Lee and Chou (2012) investigated the effects of knowledge management strategy on knowledge creation abilities of people and organizations' performance. After investigating different references and surveying several institutions, they developed the structure and hypotheses of this study. The results indicated that knowledge management strategy in an organization influenced significantly on knowledge creation ability of that organization. Moreover, knowledge creation ability had a significant impact on the individual performance.

It can be concluded that the components of knowledge achievement, knowledge transformation, knowledge application, and knowledge maintenance in Shahr Bank have great impact on the financial performance. In a knowledge-based economy, successful products and organizations can continue their existence according to the knowledge which can use these intangible assets in a better and faster way. Research indicated that despite the decrease in the efficiency of traditional resources such as money, land, and machinery, knowledge is the great source of performance promotion in the business. From the strategic viewpoint, knowledge management and intellectual capital are used to create and improve organizational values and the success of an organization based on its ability to manage this rare source. 
Gholipour, Jandaghi, and Hosseinzadeh (2010) investigated the impact of organizational knowledge management on the improvement of performance measurement system from knowledge, employees, managers, and experts of National Petrochemical Company perspectives. This study was a descriptive surveying research. The results indicated that five components of knowledge management using Filous model including achievement, recording, transfer, creation, and application had significant impacts on the improvement of performance measurement system.

Chang Lee, Lee, and Kang (2005) investigated 101 Korean companies and introduced an index named KMPI to measure knowledge management performance. They suggested that through increasing this index which includes the main components of knowledge process cycle including creation, accumulation, sharing, using and internalizing knowledge, and the indices of organization's performance which includes stock price, the rate of obtained price, and research and development prices. It is worth mentioning that the mentioned researches were in line with the subject and purpose of the study. According to the collected data, it can be concluded that components such as applying electronic communication channels for customers in order to spread marketing messages as well as buying and selling in Shahr Bank have great impact on financial performance. Venous and Salehi Maman (2005) identified the factors affecting the bank customers' tendency to use ATM bank system. Based on the results, place utility, customer awareness, system integrity, variety of services, ease of use or access, and trust are six factors which affect the customers' tendency to use ATM bank system. From the viewpoint of ATM users, trust was the most effective factor and from the viewpoint of those who do not use ATM, place utility was the most effective factor.

Pourmirza investigated the acceptance of electronic banking by Iranian customers in 2008. The results showed the fundamental differences between the demographic characteristics of customers and also their behaviors. Moreover, branch counters in banks were identified as the most popular communication channel followed by ATMs, electronic banking, telephone banking, and email banking that had the least usage among the costumers. Demographic characteristics of customers are highly related to the acceptance of electronic banking. In this study, a comprehensive realization of the efficiency of electronic banking was obtained. The results indicated that security features and low awareness about electronic banking as well as technical knowledge were the most important and fundamental obstacles of the acceptance of electronic banking.

It is worth mentioning that the mentioned studies were in line with the subject and purpose of this study. In the era of information and communication technology, knowledge is considered as the critical factor for organizations to achieve stable competitive advantage. Along with the shift from the industry-based economy to knowledge-based economy, organizations have attempted to promote their competitive power through relying on the knowledge and information in the process of business. Generally, organizations rely on two categories of assets including tangible and intangible assets. Recently, obtaining and optimizing tangible assets such as machinery and equipment had attracted the attention of organizations. However, organizations have realized that intangible assets such as intellectual capital, experience, and organizational knowledge and information will contribute to their success and survival (Shipside, 2002). Today, companies have concluded that they need to pay 
more attention to what they know or intellectual capital than what they have or physical capital (Hosseini et al., 2009).

Realizing the importance and critical role of knowledge management, organizations are encouraged to apply these systems. Due to the lack of a clear understanding of what organizations want to achieve, they cannot optimally design and implement these systems (Hsu, 2012). If the processes of knowledge management such as creating knowledge, obtaining knowledge, sharing knowledge, applying knowledge, and maintaining knowledge are applied in the organizations in a systematic and organized way, their profound impacts on creating competitive advantage in different units of organization can be observed (Slater \& Olson, 2001). In order to raise the necessity of implementing knowledge management plans as well as using information technology and competitive strategies to promote financial and non-financial performance in the organizations, it is essential to accurately identify the consequences of using these plans in different units of an organization. This study attempted to provide satisfactory answers to all these issues.

\section{References}

Abtahi, S., \& Salavati, A. (2006). Knowledge management in organization. Tehran: Peyvand Naw Publication.

Bengtsson, M., Boter, H., \& Vanyushyn, V. (2007). Integrating the internet and marketing operations: A study of antecedents in firms of different size. International Small Business Journal, 25(2), 27-48.

Bock, G. W., Zmud, R. W., Kim, Y. G., \& Lee, J. N. (2005). Behavioral intention formation in knowledge sharing: Examining the roles of extrinsic motivators, social-psychological forces, and organizational climate. Management Information Systems Quarterly, 29(1), 87-111.

Chang Lee, K., Lee, S., \& Kang, I. W. (2005). KMPI: Measuring knowledge management performance. Information \& Management, 42(3), 469-482.

Del Aguila-Obra, A. R., \& Padilla-Melendez, A. (2006). Organizational factors affecting Internet technology adoption. Internet Research, 16(1), 94-110.

Gholipour, R., Jandaghi, G., \& Hosseinzadeh, S. A. A. (2010). Explanation of knowledge management enabler as a latent variable: A case study of SMEs in Iran. African Journal of Business Management, 4, 1863-1872.

Hosseini, S. M., Ghazizadeh, M., \& Abbasi Esfangani, H. (2009). The influence of exemplary exporters of industrial sector selected 2000 to 2005. Daneshvar Rafter, 15(32), 125-141.

Hsu, S. H. (2012). Effects of competitive strategy, knowledge management, and e-business adoption on performance. The Journal of Human Resource \& Adult Learning, 8(2), 42- 49.

Kasten, J. (2011). Knowledge strategy and its influence on knowledge organization. Proceedings of the North American Symposium on Knowledge Organization, USA.

Kiang, M. Y., \& Chi, R. T. (2001). A framework for analyzing the potential benefits of Internet marketing. Journal of Electronic Commerce Research, 2(4), 157-163.

Lee, J. S., \& Chou, W. F. (2012). The effects of knowledge management strategy of an enterprise on the knowledge creation capability of R \& D team members and their R\&D performance. Journal of Operations Management, 22, 589-607.

Mehri, A., \& Khodadad Hosseini, S. H. (2005). Design a competitive advantage model for the automotive industry. Journal of Humanities, 9(2), 189-212.

Moradi, M., \& Shafahi, R. (2005). Paper of competitiveness in diamond porter’s perspective. Journal of Tadbir, 16(4), 19-22.

Pennington, D. C. (2003). Essential personality. England: Routledge.

Pourmirza, A. (2008). Accepting electronic banking by Iranian customers in 2007 (Unpublished master’s thesis). Tarbiat Modares University, Tehran.

Rust, R. T., \& Espinoza, F. (2006). How technology advances influence business research and marketing strategy. Journal of Business Research, 59(10), 1072-1078. 
Safarzadeh, S., Naderi, F., \& Enayaty, M. S. (2013). The relationship between organizational health, job engagement and innovative organizational climate with psychological empowerment in employees. Journal of Social Psychology, 8(27), 5569.

Seyed Danesh, S., Saremi Rad, N., Nejad Mobasher, S., \& Seyed Danesh, M. M. (2012). The investigation of mutual relationship of success factors of knowledge management in project-centered organizations. Journal of Basic \& Applied Scientific Research, 2(4), 3888-3896.

Shipside, S. (2002). Branding on the Internet: New international marketing issues. Management Research News, 25(12), 5362.

Slater, S. F., \& Olson, E. M. (2001). Marketing's contribution to the implementation of business strategy: An empirical analysis. Strategic Management Journal, 22(11), 1055-1067.

Venous, D., \& Salehi Maman, M. (2005). Identification of factors influencing customers' tendency to use bank automatic payment systems. Journal of Management Knowledge, 17(67), 157-185. 